1. Journal of Interdisciplinary Voice Studies

2. Volume 5 Number 1

3. (C) 2020 Intellect Ltd Article. English language. https://doi.org/10.1386/jivs_00016_1

4. Received 11 November 2020; Accepted 16 February 2020

5.

6.

\title{
On breaking with
}

\section{ABSTRACT}

It is through voice that oftentimes individuals find themselves breaking with conventions and systematically ingrained injustices. In the recent literature in the burgeoning field of interdisciplinary voice studies, the phenomenon of voicing has been projected as a powerful process, across cultures, to represent human agency at its most potent, and this article is a critical discussion on this very uniqueness of voicing in relation to social equity, corporeality and cultural value. The author, a female singer-researcher of Karnatik music of South India, unpacks the burdens and privileges of voice in the light of cultural contingency, global mobility and interculturality. Following a discussion encompassing literature and theories on voice, historical ideas of voice and feminist critiques on voice and the voicing female body from a South Indian angle, the author proposes a Pentagonal Entanglement framework for equitable engagement with the voice-across scenarios and cultures, to critically address the socially pressing issues of our time through the medium of voice.

41.

42.

43.

44.

45.

46.

47.

48.

49.

50.

51. 52.

\section{INTRODUCTION}

Building on Inchley (2015) and Stoever (2016), influential voice researcher Thomaidis (2019) has recently proposed that listening and voicing go hand in hand and are agential in politicizing sound and the bodies that are involved in the transactional relationships that such soundings sustains in society. He notes that the listening-voicing unit is an invitation'to listen-out to the sociopolitical forces and economies of signs manifested in the material concreteness

\section{KEYWORDS}

voice

South India

patriarchy

equity

culture

Karnatik

Convention

Tradition 
of each vocal interchange' (Thomaidis 2019: 3). He then offers 'listening across' 1 . as an epistemic provocation - across fields, social categories, species, modali- 2 . ties, senses and territorial spaces. This provocation relates to the subversive 3 . powers of vocal art and is suggestive of issues such as social justice and equity 4 . in the context of voicing, sensing, and sonically 'being' in this world. For, gulfs 5 . of socially imposed and accepted (often tacit) differences presuppose or some- 6 . times pre-empt a certain kind of vocal action and style of communication, as 7 . Thomaidis $(2015,2017)$ has argued over the last few years. When the ways 8. in which voice is understood changes, such a change in perspective stirs- 9 . up something very real in the social constructs that sustain signification and 10 . communication. Voice then becomes a tool through which one can break-with 11 . conventions that are prejudicial or unfair - in any respect. It also becomes a 12 . critical lens that offers multiple and interrogative perspectives on any vocally 13 . active situation.

Drawing on this premise as a point of departure, I would like to respond to 15 . Thomaidis' (2019) call for 'listening as a gesture of reaching-across' by calling 16 . also for vocally breaking with imposed boundaries - of conventions, of norms 17. and accepted vocal functionalities across performative and social contexts. This 18 . is a need of the hour to sustain key values that drive our current society, such 19 . as equity, fair representation, the power of choice and diversity (in culture and 20 . identity of person and practice). I look to my cultural and performance back- 21 . ground as a singer of Karnatik music of South India as a point of departure in 22. discussing the need to break with convention and seek newer frameworks of 23 . critical understanding in scenarios of voicing.

In voicing-listening and musically perceiving a female Karnatik performer 25. articulate emotion - as sound and gesture - there is a certain activism that is 26 . implicitly seething at the core of the exchange, which breaks with and insti- 27 . gates. This article attempts to explain why this is important to acknowledge 28 . by drawing on: the historical oppression of female singers in Karnatik music, 29. the current literature from voice studies and personal experience. It estab- 30. lishes the need for a critical evaluation of voicing in regulated and controlled 31 . cultural environments, and finally theorizes a pentagonal model that yokes 32 . 'vocally breaking-with' to 'listening-voicing' in an ethical lattice to situate 33. models of voicing, breaking-with and listening. The model is advanced as a 34 . messy entanglement of questions that confront real-life situations where voice 35 . sometimes mediates and at other times manipulates. 36.

PROCESSING VOICING: FROM A PERSONAL PERSPECTIVE

I have recently argued for the potential benefits - epistemological and methodological - of moving away from a conceptualization of voice as object towards an understanding of voice as process.

(Thomaidis cited in Thomaidis and Magnat 2017: 98)

Building on Thomaidis' and Magnat's (2017) philosophies around voicing as a processual lens to evaluate questions that are embedded in the flow of life, I consider voicing as a process of unpacking what the voice stands for, how it might be seen to experience the world and in turn be experienced by the world, as a starting point. My unpacking happens in the context of Karnatik music of South India and in that sphere, interesting meanings begin to unfold - across social, cultural and historical paradigms (Mani 2017a). Rather than 
1. considering the Karnatik - trained voice as a fixed singular idea whose single

2. defining affiliation is to culture and a certain normative vocal style, regarding

3. it as one accessible modality of bodily expression challenges current precon-

4. ceptions and dominant discourses on voice and vocal agency in the Karnatik

5. context as I have argued in Mani (2019b). It also confers on the researcher

6. an opportunity 'to radically renegotiate voice, to de-naturalize conventional

7. ideas about something seemingly so familiar and to rethink voice not as given

8. or fixed but as the plural, in-between, challenging and generative practice of

9. $\quad$ voicing' (Thomaidis 2017: 74).

10. In the context of Karnatik voice, what exactly is challenged, who chal-

11. lenges, how voicing impacts the challenger and the challenged, and why such

12. a re-negotiation of voice is a pressing need - in history and in the present

13. - are all questions related to the performing voice. While I grapple with these

14. questions on a daily basis in my current context, I also wonder how these

15. questions that apparently relate to Karnatik voice may be extrapolated to the

16. broader social scenarios that we currently inhabit, as a collective human-

17. ity. I am primarily a performer of traditional Karnatik music from Chennai,

18. India, and my 'mother voice' is Karnatik - in technique, sounding and accent.

19. However, over the last decade, I have been operating creatively in a global

20. context. I live in Brisbane, Australia, and perform Early Opera and Early Music

21. with Karnatik improvisations and interpretations. I have observed over the

22. years that in contexts where difference in styles of voicing play out, even the

23. subtlest of differences in vocal timbre and quality are amplified and acquire

24. meanings greater than just the style or technique itself. As Eidsheim (2018)

25. notes, the voice becomes the locus of racial subjectivity. It evokes images of 26. personality, gender and vulnerability, all at once.

27. I have observed that my Karnatik voice has been instrumental in confer-

28. ring identity, belonging, distinction and difference on me, almost immediately.

29. For me, the embodied presence of the voicer also links to a broader macro-

30. question of social relevance of such a voicing-based approach as opposed to

31. a voice-based approach in understanding the role of a voice, the voicer, the

32. receivers and voicing. This is not least due to my positioning in this discus-

33. sion as a female singer-researcher who is automatically instated as a musical

34. 'other' in any performance context in a Western land due to her vocal style and

35. appearance, and who, ironically, by very virtue of that appearance and vocal

36. style has been experiencing a dissociation with her own system of music, its

37. patriarchal power structures and its rules around women singers. I would

38. argue that such a linking from a micro to a macro level might be relatable to

39. other ethnic groups of voicers who might feel bound or compelled by conven-

40. tion and technique. There may be other voicers out there who wish to break-

41. free and re-negotiate their relationship to voice, beyond what they have been

42. prescribed or thought to 'represent'. Discussing prescriptions in the light of

43. history, subjectivity and current scholarship in the field of voice studies offers

44. a vantage point from which to consider such re-negotiation.

45.

46.

47.

48.

49.

50.

51.

52.

\section{KARNATIK MUSIC AND THE VOICING FEMALE BODY: CENTURIES OF REPRESSION}

Karnatik music is one of the primary classical music forms of Southern India. It has a rich history spanning several centuries, and contemporary Karnatik practice is one that leans towards conventions that were erected over the last few centuries rather than traditions that have evolved over the last 1000 years. 
Traditionally, Karnatik music was practised by members of a caste whose 1 . men were known as icai Vellalars and women as devadasis. In 2004, Tanjore 2. Viswanathan and Matthew Harp Allen declare, 'what is now considered"tradi- 3. tional" in Karnataka music performance is only just over half a century old' 4 . (86), calling for an honest evaluation of the music that is currently regarded 5 . as 'classical'. Scholarship examining the past performance cultures of Karnatik 6 . music (Krishna 2013; Terada 1996, 2000; Weidman 2001) has problematized 7. contemporary Karnatik practice, not least due to the habituated negation of a 8 . crucial element from the past in the present Karnatik construct, namely, the 9. embodied voicing style of the devadasis.

The devadasis were the hereditary female performers of classical music 11 and dance, and the 'only women to present Karnatik Music in public, in the 12 . first decades of the twentieth century' (Viswanathan and Allen 2004: 70). A 13. key aspect of their art was deliberate, semantically pertinent gesture of hands 14 . (mudras) and facial expressions (abhinaya), and movement, while singing, 15. rendering their music representational. Their repertoire constituted songs of 16 . love and longing (padams and javalis), and their bodies were loci of expres- 17. sivity and 'vocal agency' conferring on them stature across social, cultural and 18 . political levels (Thomaidis 2015: 214-16). Due to a protracted series of political 19. events in the early twentieth century, their embodied style became dissoci- 20 . ated from what was then recognized as respectable, and therefore 'classical', 21. in Karnatik music (Allen 1998: 68; Amrit Srinivasan 1985: 1875). Further, these 22. women who expressed love, lust and sentiments other than merely spiritual- 23 . ity by using their whole body as a crucible of voice, were eventually (by the 24 . mid-twentieth century) labelled as prostitutes and shunned away from public 25 . performance spaces, rendering them homeless, shamed and disenfranchised 26 . from society. They were silenced and their descendants continue to suffer this 27 . lack of vocal agency.

Around the same time, a revising of Karnatik music was orchestrated as 29 . part of the postcolonial 'nation-building agenda' by the upper-caste brahmins 30 . (Subramanian 2006: 2). Sadly, the rationale for revision hinged on the sense 31. of shame that came to be associated with the feminine singing and gestur- 32 . ing body of the devadasis (Soneji 2011). As Krishna (2013: 316) declared, the 33. function of the Karnatik kacceri form then instated was'to rid dance and even 34. music of its devadasi history'. At the root of this disturbing history of Karnatik 35 . voice is the fact that the feminine in Karnatik music has always been highly 36 . controlled, politicized and vulnerable (Krishna 2013: 314-17). As cultural 37. anthropologist Amanda Weidman notes: 38.

Ideas about femininity and the ideal woman motivate the definition of the 'classical' in South India, whether in music or dance. The question of women's participation in these fields is not simply a women's issue, or an extra-musical matter; rather, it plays a crucial role in defining the notion of what is 'classical', in defining performance, and in defining music itself.

(Weidman 2001: 132) 46.

The trend of regulating corporeal expression in women performers of Karnatik 48 . music continues today, and is tied to the notion of convention. In female 49. Karnatik singers, it is the lack of gesture and movement that is prized. When 50. a female Karnatik singer moves to express herself, she is often viewed as the 51 . nemesis of 'sweetness' that her voice ought to stand for. Rather, feminine 52. 
1. vocality has acquired a certain image of 'cultivated demureness' in the patriar-

2. chal construct that Karnatik music is encased within (Krishna 2013: 316-22).

3. Any anomaly to the epitomized godliness in the female singer is sometimes

4. considered an aberration, as this public comment from a YouTube clip of lead-

5. ing singer Aruna Sairam's performance demonstrates:'The harsh grating voice

6. of the [female] artist and unwanted theatrical gestures marred the whole idea

7. of the programme. How unsweet!' (Sundaram Sastry 2017).

8. The lack of gestural freedom in women has propelled Weidman (2001:

9. 166) to refer to female Karnatik vocal performers as 'disembodied'. She writes

10. of the notion of voice that has come to represent Karnatik music over the last

11. century: 'A particular kind of voice that was imagined to come naturally from

12. within, unmediated by performance of any kind: a disembodied voice, as it were'

13. (Weidman 2001: 166, emphasis added). A disembodied voice is not any less in

14. value compared to one that may be overtly embodied - for, voice automati-

15. cally implies a human element associated with it (Di Matteo 2015). However,

16. in the case of Karnatik music, the voice is ascribed a certain ethereal quality

17. that is assumed to slip away if tainted with corporeality. If the devadasi song-

18. dance style had continued, then perhaps Karnatik vocal music practiced by

19. female performers today might still include gesture - not only of the musically

20. contingent kind, but also of the representational kind that conveys the content

21. of the text, but this was not to be.

22. Thodur Madabusi Krishna (2013: 190), a well-known singer-scholar of

23. Karnatik music, begins his discussion on the voice by declaring, 'actually,

24. the whole body sings, not just the voice'. He follows this comment, which is

25. already indicative of a body-voice divide as taken for granted in the Karnatik

26. style, with one that locates Karnatik voice squarely in the domain of the 'mind',

27. 'the voice will be relaxed and every trigger from the mind will be expressed

28. comfortably', he writes (Krishna 2013: 190). With this comment, he reinforces

29. the classic body-mind Cartesian divide that marks the voice related scholar-

30. ship of the Karnatik field. Another well-known scholar, Pesch (1999), relates

31. the Karnatik voice to human anatomy, mapping the various tonal regions

32. and sounds to the yogic chakras, the six energy centres located in the body.

33. However, his descriptions relate parts of the body to vocal tone. He refers to

34. the literature that extols the various parts of the body as facilitators of sound.

35. Falling in line with convention, he never once acknowledges the lived expe-

36. rience held and wielded by the voicing body as it expresses. Neither Pesch

37. nor Krishna, therefore, examine the singerly body's sense of identity, passion

38. and personality that it automatically assumes as it emits sound. For instance,

39. Pesch writes, 'the nose and eyebrows serve as focal points for a type of singing

40. which aims at finer modulation', and continues to discuss the vowels ' $a$ ' and 'o'

41. in relation to the nose/eyebrow region (Pesch 1999: 66). Technicality is recog-

42. nized. But how about the intensity that the singer experiences while drawing

43. that long breath before an exclamation in the song? What about the significa-

44. tion of the raise of the eyebrow in response to an intense aching quality that

45. the voice might project at any point in the singing?

46. Two recent studies relate to Karnatik voice from an intercultural perspec-

47. tive; both these studies regard the voice as a trope for a specific musical style

48. and cultural expression, not as a crucial node of lived singerly experience

49. (Grimmer 2012; Radhakrishnan 2016).

50. From my two-decades of training and performing in Karnatik music, I

51. can confirm that the pedagogy and performance approach in Karnatik music

52. regards the body as a casing for the independently functioning, rather pure, 
virginal voice; as if any association with the flawed body might tarnish its 1 . angelic qualities in any way. Rather, the godliness and spirituality associ- 2 . ated with the music have become the very factors that have estranged the 3 . in-between enigma, the voice, from its sole bearer, the body.

As such, the ancient connections between the voice and the bodily organs 5 . in Indian music are emphasized in vedic treatises of music and education 6 . such as Narada Purana, Narada Siksha (Durga 1983). Their reinforcement is 7. evidenced in compositions such as composer Thyagaraja's Sobillu saptaswara 8. (which traces the passage of sound through the bodily chakras). However, the 9. 'organic body', which Järviö (2006) describes as the one that perceives and 10. shares feelings while making music, in the context of Karnatik music, is almost 11. always discussed in terms of the vocal sound, technique and capacity; seldom 12 . in terms of the experience of the singer. Not least the female singer. The voice 13. in Karnatik music, I contend, has become the signifier of inequalities based on 14 . class, gender and lineage.

\section{A PRESSING NEED TO BREAK-WITH, AND SOME PROMISING TRENDS}

If vocal practice is a trope for negotiating individual and collective identity, belonging, gender and representation in music, as much argument in voice studies confirms is indeed the case (e.g. Gillian 2017; Hornabrook 2017), then its underpinning constructs and philosophies must be urgently reconsidered within the context of Karnatik music, or for that matter any context in which it has been mutilated to privilege class, patriarchy, power imbalances and blind convention. A consideration of this South Asian vocal tradition through the lens of the currently burgeoning field of scholarship, interdisciplinary voice studies, might be a refreshing way to approach tradition from the angles of growth, newness and 'breaking with' rather than merely 'towing the line'. For convention is often confused with tradition.

Tradition, particularly a performance tradition involving voice, is handed down from guru to student, through history. It is subject to change based on stylistic and technical differences. Convention is handed down, more often than not, from gatekeepers of a culture to disciples and is at the service of the interests of a group or class of people. Change, however sensible, is resisted in the domain of imposed convention. Performer/activist Krishna (2013) has given a commentary on the crucial differences between tradition and convention. Tradition, while an adherence to higher principles of culture, is a flowing concept and embraces change as constructive; convention is an adherence to the dominant and ingrained 'notions' of culture and would rather embrace stagnation. Tradition is closer to the natural flow of knowledge and its stages of transformation in oral-aural traditions; convention is often a garb that is imposed on such natural order to create an aura of reverence and impenetrability. The subtle points of distinction between tradition and convention dictate the ethics of what can and must be considered as 'intangible vocal heritage' in traditional music across cultures (Thomaidis and Magnat 2017: 101) and what could be masquerading as such 'heritage'. A voicer, at each moment, has the power to pick one of the two - in non-western and western contexts alike. If it is parampara (a word describing convention in the Karnatik fold) that is the gatekeeper in the Karnatik singing style, it is ideas around werktreue, textreue and text-fetishism that constrain and label singers of Western Art Music, as Taruskin (1995) and Goehr (1992), among many others, point

4. 7. . . 14. 
1. out. The Karnatik and Western principles and traditions are indeed different;

2. convention across both systems, I contend, is however predicated on the issue

3. of 'control' - of who voices; who listens; who ought to listen better and across;

4. whose voice ought to be heard more; why voicing happens; how it unfolds

5. - as content, intent, passion and process, what ought to be voiced; and what

6. facets of human existence are revealed, politicized and propagated through

7. voice; what is left unsaid and un-listened (not unheard). For as Nancy (2007:

8. 9) notes, listening (as opposed to hearing) is spatial and relational, a referent

9. (renvoi) between the voicer and receiver. Overall, control has implications - in

10. relation to gender, context and society.

11. It is issues of control that have dominated the ways in which voice, which

12. is one of the basic human rights of an individual, has been and contin-

13. ues to be used in musical and extra-musical contexts across history. Cathy

14. Berberian's voice is a case in point. Her Monteverdi operas were markedly

15. different - unconventional, as were her persona and vocal quality. Her devia-

16. tion from the normative and the controlled constructs of the early music voice

17. marked her voicing process that now testifies to an important link in the

18. flowing tradition of Early music connecting work and text to possibility and

19. modernity in performance. Andrea von Ramm's depictions of Early music are

20. another example where voice thwarts convention, and in doing so perpetuates

21. a boldly developing tradition. Women were assigned laments in Early opera

22. (mad scenes later!) and were painted as those whose utterances were tear-

23. jerkers for the audience (McClary 1989). Their voices were used by the clever

24. court chroniclers of the time, including Federico Follino ([1608] 2004), as tools

25. to support constructs of womanhood and their behaviour in early modern

26. Europe; he reports of women in the audience watching Arianna (1608) -'there

27. was not a lady who failed to shed a tear'. The history and criticisms of opera

28. from a feminist angle are testament to such use of voice as a tool to propagate

29. the messages of the powerful and privileged, as much literature evidences

30. (e.g. Clément 1988). In Karnatik music, there have emerged feminine voices

31. that have been instrumental in throwing the Indian subcontinent into billows

32. of change at a most crucial time in its historical struggle for independence.

33. During the Indian freedom movement (early 1900s), on the one hand Madurai

34. Shanmukhavadivu Subbulakshmi's sweet voice proclaimed the nationalist

35. spirit with songs such as Vaishnava Janato in compelling tones, and on the

36. other Damal Krishnaswamy Pattammal's thick and gravely tone aroused patri-

37. otic fervour through Tamil songs such as Adu Ratte. However, their Karnatik

38. performances around the 1940s that would herald them as leading musicians

39. of their time would betray no earthy such emotion. Their onstage personae

40. were tailored to suit patriarchal constructs of performing womanhood, as

41. Krishna (2013) attests.

42. In my own experience as a well-established performer of Karnatik music, I

43. had been groomed never to express my voice in relation to my body. I remem-

44. ber my guru saying to a 17-year-old me that not even an eyebrow must move;

45. that people in the audience should wonder where such vocal sweetness was

46. coming from. It was almost like I had to be a conduit that allowed for a certain

47. prescriptive ethereal voice to somehow magically emerge from my insignificant

48. encasement of a body. Two aspects come through strongly for me, reflecting

49. on my guru's comment from the past, at this point in my life as a practitioner/

50. scholar. Firstly, in Karnatik music training, the corporeality and materiality of

51. the voice is not just ignored; it is systematically denied agency. Back then, in

52. the 2000s, I would desperately try to ignore my body. Consequentially, now I 
1. To see a performance of this, please go to: https://www.youtube com/ watch?v $=8 c \times 4 \mathrm{Kmw}$ nM4mp;feature=youtu. bemp; $t=238$, and in particular, listen to the song from 03:55. recall that I would often feel fettered after a performance, never knowing why. 1. My neck and head would regularly spasm. I would feel unsatisfied, as if I am 2 . deceiving myself.

It was around 2007 that I broke free from negating myself experienced 4 . bodily emotion and movement in voicing. This moment of truth dawned 5 . on me when I experienced a vocal chord haemorrhage due to overuse, and 6 . this unfolded in the centrality of the primary musical festival in Chennai, the 7 . December Music Season, 2006. I had whipped my voice, treating the tired 8 . horse with brutal discipline and no love or awareness! I was literally silenced 9. for around eight weeks to allow for a full recovery and had to cancel over ten 10 . concerts. I was shattered in body and spirit and spent hours in silent remorse. 11. It was in early 2007 that I went on a journey of rediscovering my relationship 12 . with my voice and my body. Self-care for the voice led me to respecting my 13. need for bodily awareness and freedom - in where, why, how, what and when 14 . I use my voice. My voice soon became a vehicle of holistic expression of my 15 . emotions, as my work from 2007 onwards testifies (Mani 2007-15).

In my Ph.D. that came much later in 2019, I found myself shedding layers 17. of repression and embracing my body-voice relationship through the trope 18 . of gesture. In The Thiruppavai Project, I composed and sang Tamil poetry in 19. a dramatic manner, adopting early operatic style of intonation and expres- 20 . sion (see Mani 2018c and Mani 2017b). For example, in my performance of 21. Thiruppavai, I allow my contextual expression to dictate both the musical 22 . phrasing and my vocal inflections. ${ }^{1}$ The Karnatik mark of vocality, the gamaka 23. ornament, is repurposed as a tool to convey emotion (in this case of a gentle 24 . sway and relaxation that is brought about by the soft light from a wick lamp), 25 . and not as a cerebral technique or marker of prowess. 26.

As such, sifting through history, across Karnatik and early operatic tradi- 27. tions, I have come to believe that just because we are singers who do follow 28 . certain styles of voice in performance, we need not be expected to sign off our 29 . basic right of voicing - as tactile, visual and sensual multimodal expressions 30. (Bonenfant 2013; Eidsheim 2015; Thomaidis 2019). Likewise, just because 31. societal conventions dictate a certain way of vocal communication, these need 32 . not supersede our individual/unique racial and gendered vocal traits. Voicing 33 . that acknowledges the entirety of our body and personality, and that is like- 34 . wise acknowledged by others in a similar manner is demonstrative of an ethi- 35 . cal approach to respecting one's sonic/visual environment. Voicing is a basic 36 . right that could to be expressed on individual, even idiosyncratic terms rather 37. than in collective, conventional terms. The subtle difference in individual 38 . and collective castings of voice has also been discussed in Thomaidis (2013a, 39. 2013b) from an intercultural perspective in opera. In short, I believe that being 40 . at the service of a cultural tradition is different from being servile to imposed 41 . convention.

Through my doctoral research journey, I slowly learned the power of 43 . choice, and this learning happened the hard way. Choosing the route of flow- 44 . ing with tradition rather than freezing under convention was a challenging 45 . way to experience musical and extra-musical modes of breaking with norma- 46 . tive approaches to vocal expression. Of the few key projects that became 47 . central to my development as an artist and researcher between 2017 and 2018, 48. the earlier mentioned Thiruppavai Project was significant. However, it was in 49. Monteverdi Reimagined, that closely followed the Thiruppavai Project, that I 50. chose to allow my embodied voice to become a canvas of expression that fully 51 . clasped the emotion undergirding the text. For the first time in my life I found 52. 
1. myself morphing into the character that was speaking/singing. Incorporating

2. the musical features typical of Karnatik music, including raga and gamaka,

3. within the dramatic constructs of opera, displaced both myself and the musi-

4. cal system from our familiar entrapments of convention. The vignette below is

5. an extract from my journal entries that were made soon after my first perfor-

6. mance of Monteverdi Reimagined. It pertains to a section beginning with 'tanta

7. bellezza' from the Act III landmark aria 'Possente Spirto' (Monteverdi's 1609

8. favola in musica, L'Orfeo). ${ }^{2}$ The section traversed into a Tamil poetry that I wove

9. into a raga.

10.

11.

12.

13.

14.

15.

16.

17.

18.

19.

20.

21.

22.

23.

24.

25.

26.

27.

28.

29.

30.

31.

32.

33.

34.

35.

36.

37.

38.

39.

40.

41.

42.

43.

44.

45.

46.

47.

48.

49.

50.

51.
52.

\begin{abstract}
Variations present themselves in raga Natakurinji. I am feeling momentary joy, as Orfeo. I leave the raga in suspended animation.

I turn to touch my silk scarf. I feel its limpness, drape it on myself.

I become Euridice. I continue in Tamil 'kannil theriyudoru totram, adhil

Kannan azhagu muzhudillai' . . 'I can see a form of my beloved that is brimming with beauty'. I express a mad hope, imagining Orfeo standing before me. All this while my voice is moving with me. It just comes along, like a good old friend. No questions asked.

The tenor of the next line changes: 'I cannot see his smile, alas! He has disappeared . . .' I sense my face crumpling, I can hear my voice trembling at the loss of hope. I am the body-voice. My voice surprises me with its ever-supportive presence. I have never felt more loved by my voice, ever. I have never loved my voice this much, ever.
\end{abstract}

This article, in essence, shares my rationale on why making a choice in the way in which we use our voice is crucial, notably in situations that carry with them the burden of convention. Voices are now being reconfigured in a globalized world. Reconfiguration, I argue, first needs to begin on the inside of tradition and then spread out as emboldened interrogations of convention.

The bodily experience of a Karnatik singer has been identified by a few critics as an area that has been arguably ignored and affording for further research (Durga 1983; Weidman 2001). Amanda Weidman (2001: 160-61) has stated her concern that the voice in Karnatik is complicit in the 'nonperformance' of performance, a sense of ignoring the felt. There has been little research or practice by way of response. On a global level, studies that yoke the voice to the corporeal have burgeoned over the last several decades in the arena of voice studies in the West, and inevitably draw on the phenomenological perspectives of Husserl ([1907] 2001) and Merleau-Ponty ([1945] 1993). Over the last decade or so, they have become increasingly interdisciplinary, spanning across performative, gendered and philosophical paradigms (e.g. Cavarero 2005; Dolar 2006; Macpherson 2012, 2015; Poizat 1992; Thomaidis 2013a, 2013b, 2014).

Over the last few decades, the noun vocality has also emerged as a powerful term linking the human voice to the shaping of cultural construct in various performative contexts (e.g. Dunn and Jones 1994; Dunsby 2004; Schlichter 2011). 'Embodied vocality' has been addressed in voice studies, performance studies, opera and cultural studies, in the context of problematizing the body as the keeper of voice (e.g. Koskoff 1989: 10-11; Thomaidis and Macpherson 2015: pp. 3-9). This term has found wide application. Karantonis et al. (2016: 47-51), for instance, in exploring the voice of Cathy Berberian, a key figure in the Early Musical revival of the 1960s, use the term 'feminine vocality' in conjunction with 'new vocality' to describe her bold non-conformance.
2. To see a performance of this, please visit https://www.youtube com/

watch?V=9SzMfVtH

QmQmp;feature=youtu bemp; $t=1921$ 
'Corporeal vocality' (Macpherson 2012) and 'physiovocal' approaches to sing- 1. ing (Thomaidis 2014) regard vocality as intertwined with the physical gesture 2. in the performing body, as I have articulated in Mani (2017b). In regarding the 3. voice as the 'paradoxical keeper of both linguistic utterance, and the bodily 4 . presence of the speaker/singer', Macpherson (2012: 43) advocates for corpo- 5 . real vocality that connects voice to language, and voice to the body; he argues, 6 . 'our essential experience of voice is an embodied one'.

Research on training actors' and opera singers' voices using intercultural 8. vocal approaches is gaining traction (McAllister-Viel 2018; Thomaidis 2013a, 9. 2015). Both McAllister-Viel and Thomaidis employ techniques from Korean 10. vocal art, p'ansori and other 'somatic' Eastern practices to reconsider vocal 11. training in mainstream actors and singers, respectively. They advocate for the 12 . living body (soma) to be acknowledged as the site where the sensory inputs 13 . are both cognized and manifest. Approaches such as those of McAllister-Viel 14 . (2018) and Thomaidis (2013a, 2013b, 2015) present pertinent examples that 15. call not only for interdisciplinary approaches to the voice, but also intercultural 16 . perspectives on the voice that may suit the global performer of today. 17

Comparably, an advocacy for privileging the role of the body in vocalizing 18 . is on the rise in the West, with Järviö (2006, 2015), Thomaidis (2013a, 2013b) 19. and Belgrano (2018) contributing specifically to the contexts of early opera, 20. bel canto pedagogy and ornamentation, respectively. 'When she is singing, a 21. singer is powerfully aware of the experience of the interiority of her body', 22 . notes Järviö (2015: 26), in calling for a foregrounding of the lived bodily expe- 23 . rience of the singer. Her approach, which derives from that of Michel Henry, 24. stems also from a resistance to the ignoring of the performing body: 'Early 25 . Music Studies tend to ignore the embodied experience of the present-day 26. performer, even though many of the authors have been performing musicians' 27 . (Järviö 2015: 25).

Further, I believe that an acknowledgement of vocality in female Karnatik 29. singers is related to the power that such an acknowledgement can confer on 30 . them. Thomaidis' (2015) comment contextualizes the notion of agency in the 31. crucial matter of voicing in an intercultural hybrid context: 32.

When borders are crossed, questions around voice become much more 34 . complex. Who, how and what voices express become less pertinent than 35 . who has agency in voicing, who has agency in listening, who benefits 36 . from voicing, and in what ways.

(Thomaidis 2015: 215) 38.

Voice is a material and metaphorical trope for arguably everything that a 40 . female persona could represent in Karnatik music or in any performance 41. practice. This argument is bolstered by Virno's (2003: 44) observation, 'the 42. ceremony of voice [...] makes the speaker visible as bearer of the power of 43 . speech' (trans. Di Matteo 2015: 91). When the female voice assumes embodi- 44. ment, the voicing female body, could assume agency, empowerment and self- 45 . determination. In the wake of the recent uprising within the field in relation 46. to the \#MeToo movement in Chennai, the key features of agency, voice and a 47 . self-assertion of one's own corporeality have emerged as the most significant 48 . necessities for a female Karnatik performer of today (Nathan 2019). 49.

Sound studies texts that focus on the human voice have burgeoned, 50. including Novak (2015) and LaBelle (2014), and these notably look to the 51. voice-body as a material cognate that assumes signification across multiple 52 . 
1. levels - physiognomy to social presence and further, to agency. In her influen-

2. tial paper from 2011, musicologist and vocal pedagogue Nina Sun Eidsheim

3. makes a pertinent observation: 'analyses of sound and music, albeit contin-

4. uously negotiated and defined, cannot be divorced from a socio-histori-

5. cally bound consideration of its material condition and sensuous pulsation'

6. (Eidsheim 2011: 149). Displacing singing from the air as a medium to the bath-

7. tub and studying the willing subject opened possibilities of rethinking the role

8. of the senses in conveying, perceiving and receiving voice. She argues that

9. notations or visual representations of voice cannot communicate those unique

10. experiences that listening for and listening to singing - of oneself and the

11. other - can. Her sense-based consideration from 2011 moves into an interro-

12. gation of Derrida's relegation of the physicality of the body in his logocentric

13. philosophy of voice; the vocal theories of Dolar (2006) and Cavarero (2005)

14. and arrives at a reconsideration of voice that locates the physical actions of a

15. voicing body as central.

16.

\section{A PENTAGONAL LATTICE OF ENTANGLEMENT: CALLING FOR EQUITY IN VOICE}

Using the above critical discussion on what the voice-body cognate stands for in the Karnatik tradition as launch pad, I propose a pentagonal framework for equitable engagement with the voice as a conceptual extrapolation. This framework is a tangled mess that mirrors real-life situations of voicing and listening wherein 'breaking-with' unfolds - intentionally or unintentionally. Its design is anything but neat, as Figure 1 evidences. It is advanced as conceptually derived knowledge that is extrapolated from juxtapositions of my lived empirical experience against theories and current critical literature in the field. As part of the Pentagonal Entanglement, I offer five key dimensions across which one can evaluate whether and how the engagement with the voice is equitable (or not). Across these five dimensions I erect a conceptual model to evaluate and assess situations involving voicing - from music to drama to politics - on whether the voiced, the voiced, and the material voice are all treated equitably.

The five interrogative dimensions are as follows:

- Who is the voicer? Who are the listeners? Who is not allowed to voice? Who does not listen? This encompasses gender identity, ethnicity, whether they may be of a marginalized group (including underrepresented denominations such as women, children, the disabled and those belonging to the LGBTQ+ communities).

- What are they voicing? What are they not? This encompasses content and tacitly imply context. In the case of music and/or speech, this tacit strand might comprise genre, technique, timbre, stylistic detail, intonation and accent of language, as applicable.

- Where does the voicer's sound assume significance - according to the voicer and the listener? This aspect brings to bear on the socio-political aspects of voicing and the porous veils of communication that are erected in situations of voicing.

- How are they voicing? Are they following an established model of sounding or are they breaking-with convention? How are they expecting to be the listened to? How are they listened to? This aspect reflects the intent of the voicer, the intent of the listener, their psycho-physical state and 


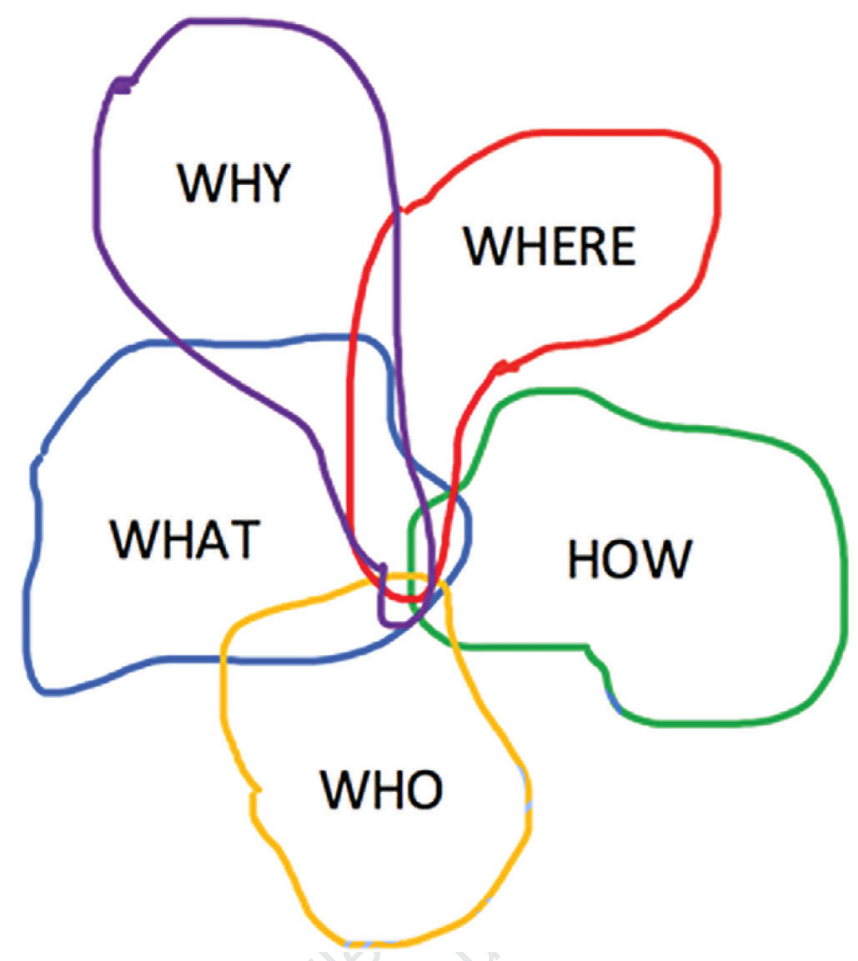

Figure 1: Pentagonal entanglement for equitable engagement with the voice.

cultural embeddedness, and also borrows from the tacit aspects outlined 29 . in the 'What' section.

- Lastly, and importantly, why is the vocal event happening at all and why 31. are the vocal choices made the way they are (at a certain place, at the 32 . given time, in a certain manner of expression, using a certain intonation, 33. initiated by a certain person in the presence of certain others). This factor 34 . relates to the ontological and phenomenological premises at interplay in 35 . situations of voicing.

The above model is porous, allows for intersubjectivity to emerge across 38 . all five prongs while also presupposing empathy, in line with the philosophies 39 . of Cavarero (2005) and LaBelle (2014). Across the above five factors, affective 40. states of the voicer, the processual approach to voicing, and the magnetic force 41. of the irrefutable materiality of the voicing body that attracts all other socio- 42 . cultural aspects to itself, emerge as vital. The element of physicality is impor- 43. tant to Eidsheim (2015); she has offered a reconsideration of speech that is 44 . focused on action or gesture: $\quad 45$.

There is another way of thinking about signification in relation to the body's actions [...] that does not rely on fixed, a priori positions or on mutually exclusive categories of originals and copies.

(Eidsheim 2015: 124) 50 
1.

2.

3.

4.

5.

6.

7.

8.

9.

10.

11.

12.

13.

14.

15.

16.

17.

18.

19.

20.

21.

22.

23.

24.

25.

26.

27.

28.

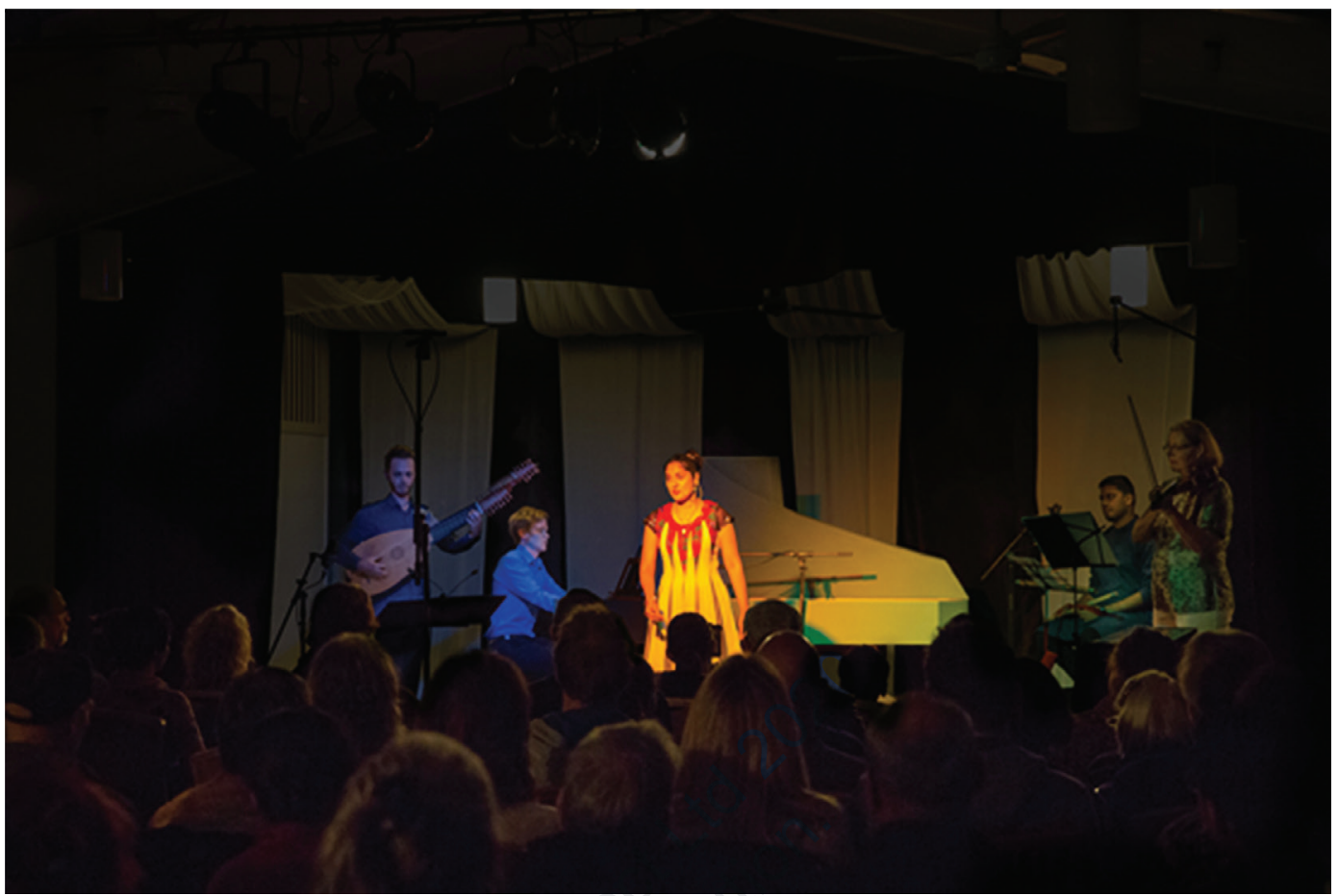

Figure 2: Monteverdi Reimagined (2017): Performing Italian opera with Karnatik vocality in Brisbane.

Photography (C) Michelle Vine, used by permission.

Physicality and a need to privilege the sensorial aesthetics of the voicer reside at the centre of my rationale to put forth this model. The sound produced by the voice assumes meaning not only when it is heard, but when it is seen - as belonging to a warm, pulsating body - that is perfect in its imperfection as an angel of living sound that is unpredictable, ever-present, fallible, powerful and vulnerable. The root of paradoxes.

Over the last few decades, voice studies has been an effective lens to problematize and understand Opera, theatre, politics, gender, agency, power imbalance, collective notions of tradition and culture, global approaches to music education and preservation of endangered vocal traditions, to mention but a few areas of impact. In the era of the global voicers and receivers, and in the current world where issues of gender and diversity are increasing assuming primacy, imbricating these strata of issues and finding links to societies and conventions which might benefit from a recalibration might be worthwhile. Academia and practice in art are often considered as disjointed and in a state of tension. However, in my view, an academic discussion around practice such as this could be one way to open-up vaulted systems of patriarchy and assumption to scrutiny that is respectfully assembled - using evidence rather than conjecture - and geared towards positive change.

\section{EXEMPLIFYING BREAKING-WITH THROUGH VOCAL PRACTICE}

Assuming the role of an intercultural performer of a 'hybrid' opera constituting a re-imagination of seventeenth-century Italian composer Claudio Monteverdi's opera, L'Orfeo, in the performance of Monteverdi Reimagined I 


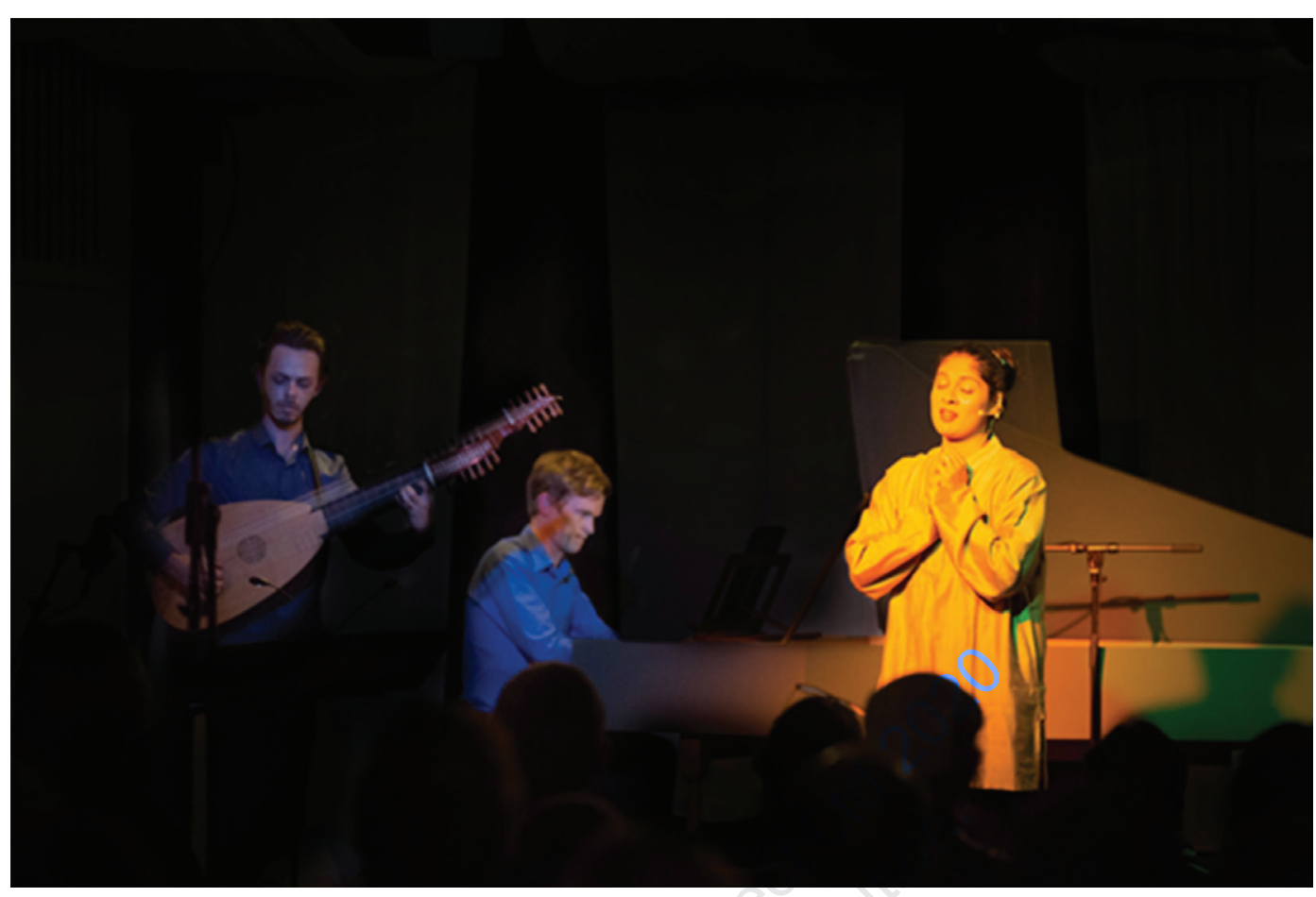

1.

2.

3.

4.

5.

6.

7.

8.

9.

10.

11.

12.

13.

14.

15.

16.

17.

18.

19.

20.

21.

22.

23.

24.

25.

Figure 3: Monteverdi Reimagined (2017): Appealing to the boatman to release the wife Euridice, as Orfeo. 26.

Photography (C) Michelle Vine, used by permission. 27.

demonstrated an approach to Karnatik voice that drew on the experiences of 28 . the organic body - as feeling, as agency and as the keeper of identity (Mani 2018b). I evaluate each of the factors stated above in the light of my empirical experiences in performing Monteverdi Reimagined in October 2017 (see Figure 2). I also draw on my encrusted life experiences as a singer who straddles between cultures and languages.

\section{Dimension 1: Who?}

As a voicer inhabiting both Karnatik and operatic worlds, my voice is a signi- 37 . fier of cultural nomadism with not one but many homes. The 'Who' that 38 . voices is complex identity. Those who are listening represent a complex milieu. 39. Inclusivity and equity are both key aspects in unpacking the identity that is 40 . conferred on the voicer and listeners in such contexts. The journal entry below 41 . alludes to the complexity of voicing an Early modern Italian opera in Brisbane, 42. Australia, in a South Indian Karnatik vocal style, along with early musicians, 43. to a multicultural audience.

I am backstage. Ten minutes to go for the curtain. A scene from my visit to Mantua: the ducal palace room, suddenly jumps into my head. I see the turrets, and the piazza adjoining it. I am back in the present. I hear excited chatter in my mother tongue, Tamil. That would be my family visiting me from Chennai. I hear the occasional Australian diphthong reminding me of where I am. The clinking of wine glasses in the foyer 
1.

2.

3.

4.

5.

6.

7.

8.

9.

10.

11.

12.

13.

14.

15.

16.

17.

18.

19.

20.

21.

22.

23.

24.

25.

26.

27.

28.

29.

30.

31.

32.

33.

34.

35.

36.

37.

38.

39.

40.

41.

42.

43.

44.

45.

46.

47.

48.

49.

50.

51.

52.

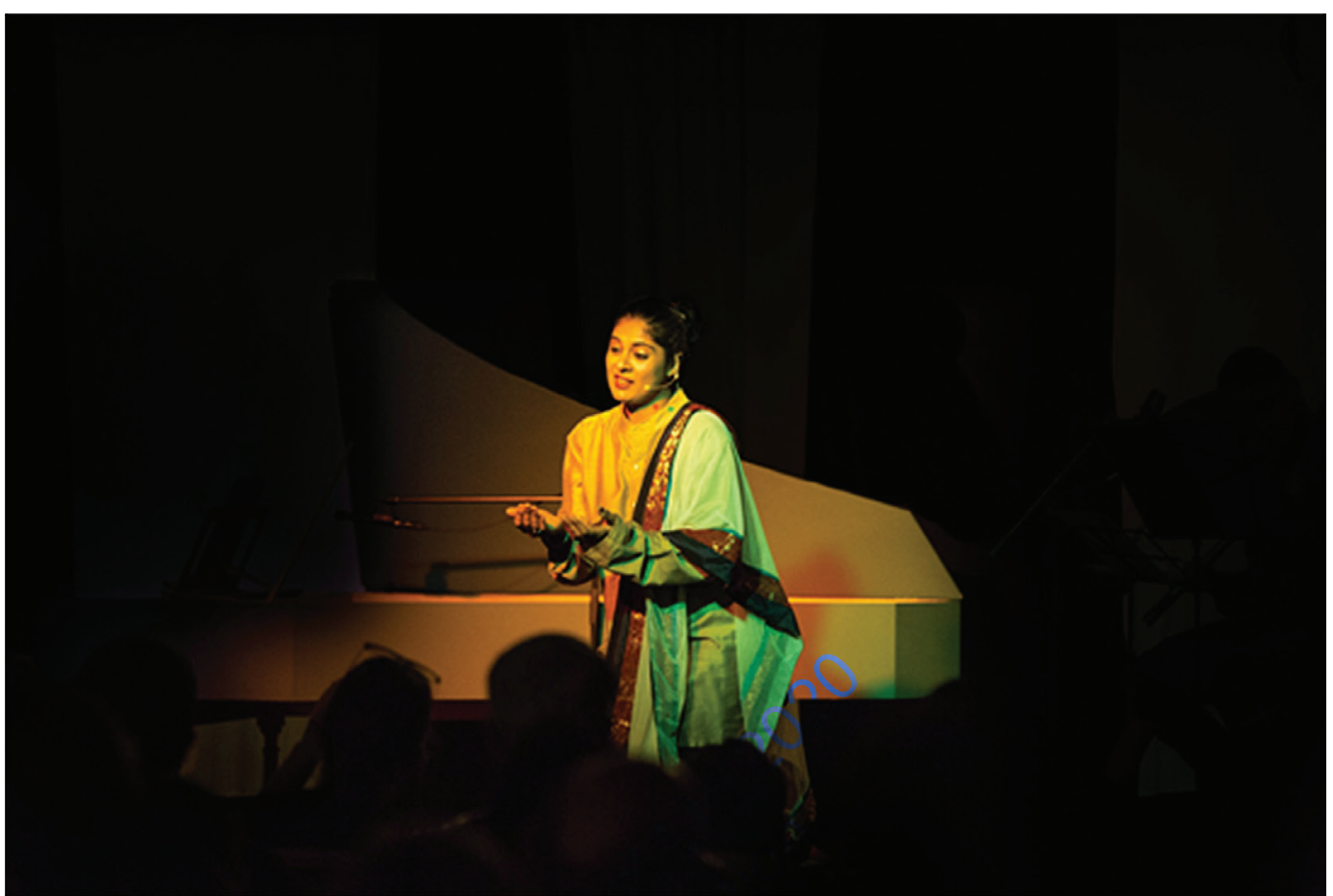

Figure 4: Monteverdi Reimagined (2017): Role doubling as Euridice in a Tamil lament in response to Orfeo. Photography (C) Michelle Vine, used by permission.

blends in with the smell of samosas. The multisensorial burst turns into a blur. It is time to sing.

\section{Dimension 2: What?}

In the opera production, I played both Orfeo and Euridice challenging gender and its significations for voice. I sang in both Italian and in Tamil and I brought a historical seventeenth-century Italian dramatic masculine appeal from Orfeo face to face with a gentle nineteenth-century feminine lament from Tamil literature. The 'What?' factor and its implications to evaluate the content, intent and context of a situation of voicing is exemplified here. Figure 3 shows me as Orfeo, and in Figure 4, Euridice takes over. Based on 'what' is being said and heard, inclusivity and equity can be established, questioned, and critiqued.

\section{Dimension 3: Where?}

The 'Where?' factor pertains to the politics of belonging and identity. In Monteverdi Reimagined, bi-musicality, bi-linguality and singer-composer duality were evidenced in the culturally diverse context of Brisbane, Australia. If audience taste is considered a marker for calibration of the voice, then such a parameter answers to the 'where' factor, and is culturally contingent.
3. To listen to the particular experience relating to this discussion, please visit: https://www.youtube. com/

watch?v=9szMfVtH QmQmp;feature=youtu be, and listen from 31:58. 


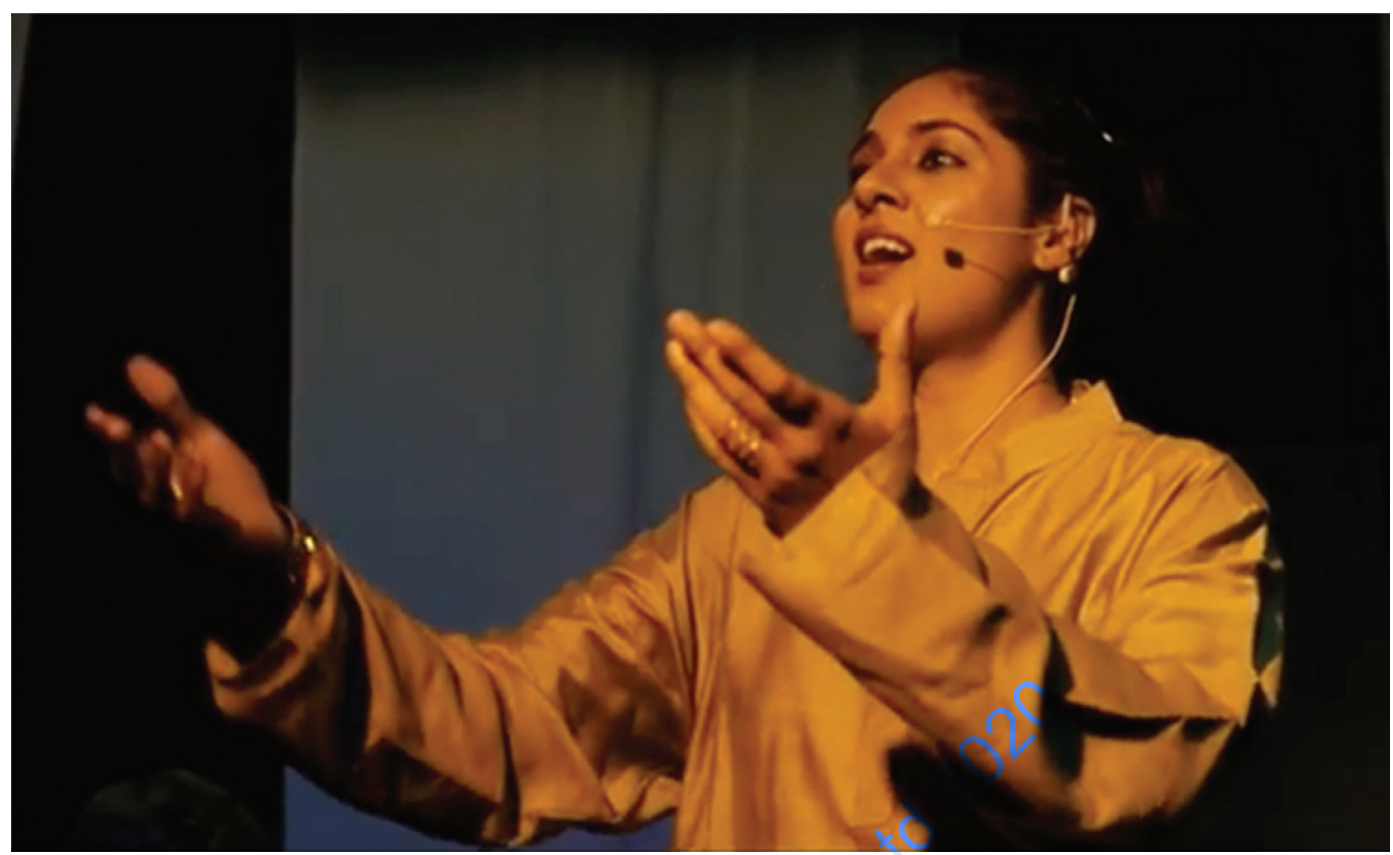

1.

2.

3.

4.

5.

6.

7.

8.

9.

10.

11.

12.

13.

14.

15.

16.

17.

18.

19.

20.

21.

22.

Figure 5: Monteverdi Reimagined (2017): Dramatic gesture: So much beauty! Photography @ Michelle

\section{Dimension 4: How?}

The 'How?' factor in voicing is often understood and expressed in terms of aurality; however, as Eidsheim has noted (2015), descriptors of voice are multisensorial. Experiencing vocal liminality at the interstices of vocal expression, including word, gesture, movement and emotion is outlined in a pedagogical context in Mani (2018a). The experience below pertains to a section in the opera production of Monteverdi Reimagined. ${ }^{3}$ This is the point wherein Orfeo momentarily thinks of Euridice's beauty and associates it with paradise. My hand gestures at 'tanta' begin as dramatic (Figure 5). Figure 6 shows the gesture soon transform into a singerly, metaphorical expression of the vocal ornament gorgie (Mani 2019a). When the passage reposes at 'bellezza', the dramatic side of gesture takes over yet again. Together the sound, gesture, posture and facial expression contribute to the descriptors on 'how' voicing happens. Such a breadth of consideration ensures that different kinds of bodies are treated with equity in voicing scenarios.

The voicer claims agency in deciding which direction to proceed in musically, visually and linguistically, at any point in the process, and therefore exercises the power of vocal choice. The right to choose is an ethical position that is strongly situated in the 'Why?' factor in voicing. The ways of being of the voicer, their ontological position, determines this choice. Such choice privileges cultural diversity and challenges normative modes of being.

An example of such choice comes from my everyday experiences. I am a stutterer and have overcome this problem slowly over the last few decades. 


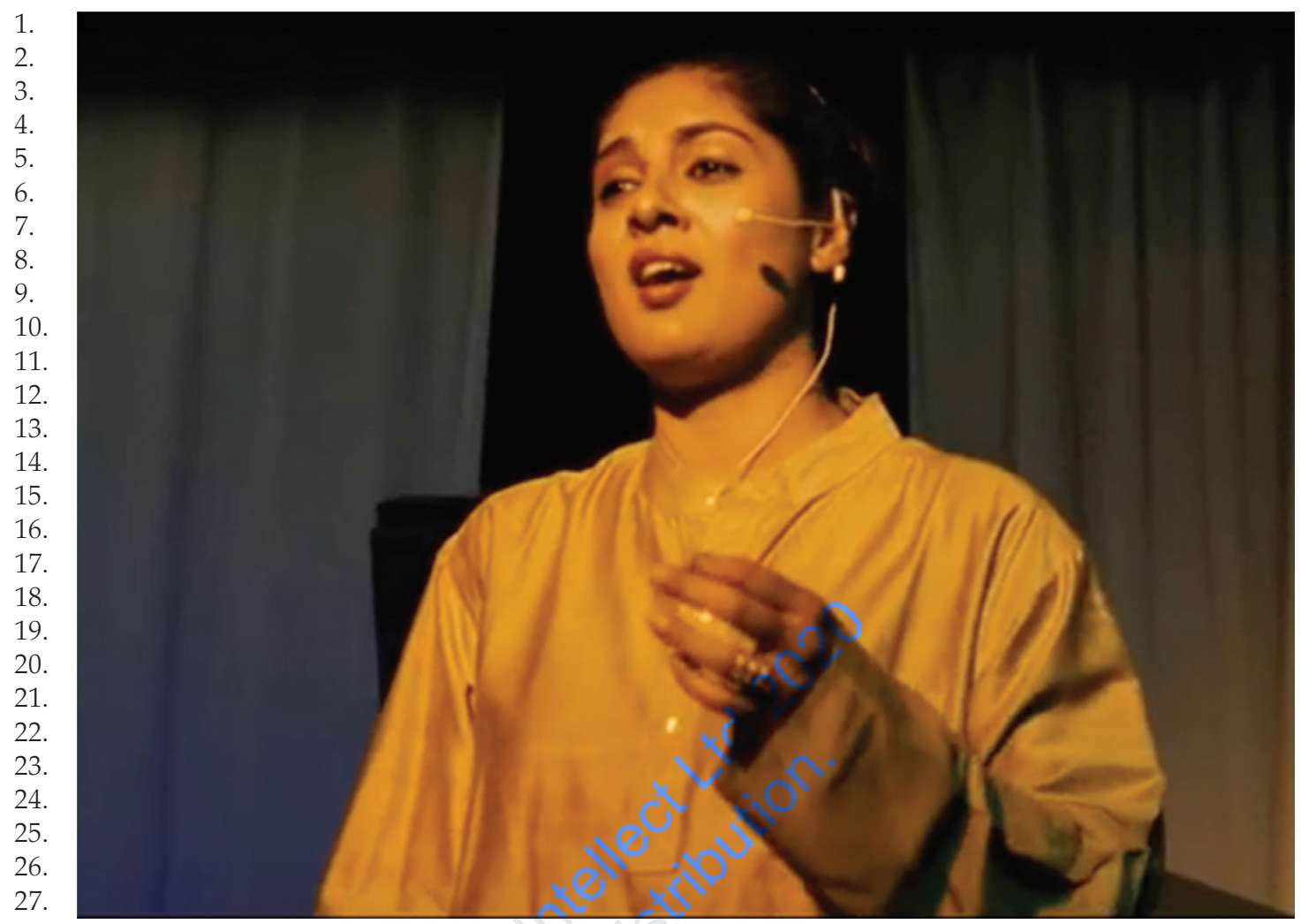

48. understand the ways in which the factors of who, what, how, when and where

49. emerge in such scenarios, but to understand how we, as voice researchers,

50. can critically examine how these factors may contribute to a reconsideration

51. of voicing scenarios in a more equitable and inclusive manner. For instance, it

52. may be argued that my experience as a stutterer challenges ableism in voicing. 
This article comes at a time when global scholarship in interdisciplinary 1 . voice studies is turning towards a critical reconsideration of the positional- 2 . ity of the voicer, their environment and their audiences. In her recent book, 3. The Race of Sound, Eidsheim (2018) demonstrates the qualifying of race and 4 . racial subjectivities through sound and vocal timbre by both the audiences 5 . and artists. Her tacit links from 'who' is singing to 'who' is listening suggest 6 . a network of cultural and political implications for the voice. Overall, across 7. musical, historical and social contexts, it is only through such radical reconsid- 8 . erations of that which is taken for granted that we can evolve as a collective 9 . humanity of empathetic voicers and listeners. I humbly submit that the frame- 10. work proposed here could find application across contexts that beg social and 11 . cultural justice through the powerful intra/inter-personal lens of the human 12 . voice.

ACKNOWLEDGEMENTS

Monteverdi Reimagined was made possible through a Griffith University Postgraduate Scholarship Award during my Ph.D. My thanks are due to Professor Stephen Emmerson and Dr. Catherine Grant for their guidance. The photographs are by Michelle Vine, Brisbane.

\section{REFERENCES}

Allen, Matthew (1998), 'Tales tunes tell: Deepening the dialogue between 23. "classical" and"non-classical" in the music of India', Yearbook for Traditional Music, 30:1, pp. 22-52.

Barker, Paul (2015), 'Foreword: Disambiguating sung and spoken voices 26 . through a composer's experience', in K. Thomaidis and B. MacPherson 27. (eds), Voice Studies: Critical Approaches to Process, Performance, and 28. Experience, Oxford and New York: Routledge, pp. xiv-xxvi.

Belgrano, Elisabeth (2018), 'Ornamenting vocality. Intra-active methodology 30. for vocal meaning-making', Ruukku Studies in Artistic Research, 9, doi: 31. 10.22501/ruu.370801. 32.

Bonenfant, Yvon (2013), 'Writing touch in textile: Talking touch in tactility', 33. Journal of Dance \& Somatic Practices, 5:2, pp. 121-39. 34.

Cavarero, Adriana (2005), For More Than One Voice (trans. P. Kottman), Stanford, 35. CA: Stanford University Press.

Clément, Catherine (1988), Opera, or, the Undoing of Women (trans. B. Wing), 37. Minneapolis, MN: University of Minnesota Press. 38.

Derrida, Jacques (1982), Margins of Philosophy (trans. A. Bass), Chicago, IL: 39. University of Chicago Press.

Di Matteo, Piersandra (2015), 'Performing the entre-deux: The capture of 43. speech in (dis)embodied voices', in K. Thomaidis and B. MacPherson 44. (eds), Voice Studies: Critical Approaches to Process, Performance and Experience, 45. Oxford and New York: Routledge, pp. 90-103. 46.

Dolar, Mladen (2006), A Voice and Nothing More, Cambridge, MA: MIT Press. 47.

Dunn, Leslie and Jones, Nancy (eds) (1994), Embodied Voices: Representing 48. Female Vocality in Western Culture, Cambridge: Cambridge University Press. 49.

Dunsby, Jonathan (2004), Making Words Sing: Nineteenth- and Twentieth- 50. Century Song, Cambridge: Cambridge University Press. 
1. Durga, S. A. Kumari (1983), 'Indian literature on vocal abuse', Asian Music, 2. 15:1, pp. 1-10.

3. Eidsheim, Nina Sun (2011) 'Sensing voice: Materiality and the lived body in 4. singing and listening', The Senses and Society, 6:2, pp. 133-55.

5. - (2015), Sensing Sound: Singing and Listening as Vibrational Practice, 6. Durham and London: Duke University Press.

7. - (2018), The Race of Sound: Listening, Timbre, and Vocality in African 8. American Music, Durham, NC: Duke University Press.

9. Follino, Federico ([1608] 2004), 'Compendio delle son tuo se feste fatte l'anno 10. MDCCVIII nella citta di Mantova, perle realinozze del serenissimo pren11. cipe D. Francesco Gonzaga con la serenissima infante Margherita di Savoia, Facsimile', in C. Gallico (ed.), Cronache Mantovane, Florence: Olschki, pp. 83-84.

Gillian, Matt (2017), 'Constructing the singing voice: Vocal style, aesthetics, and the body in Okinawan music', Journal of Interdisciplinary Voice Studies, 2:2, pp. 103-17.

Goehr, Lydia (1992), The Imaginary Museum of Musical Works: An Essay in the Philosophy of Music, Oxford: Clarendon Press.

Grimmer, Sophie (2012), 'Creativity in perpetual motion: Listening in the development of expertise in the Karnatic classical singing tradition of South India', Music Performance Research, special issue, 5, pp. 79-95.

Hornabrook, Jasmine (2017), 'South Indian singing, digitial dissemination, and belonging in London's Tamil diaspora', Journal of Interdisciplinary Voice Studies, 2:2, pp. 119-13.

Husserl, Edmund ([1907] 2001), The Idea of Phenomenology (trans. L. Hardy), Dordrecht: Kluwer Academic Press.

Inchley, Maggie (2015), Voice and New Writing, 1997-2007: Articulating the Demos, London: Palgrave Macmillan.

Järviö, Päivi (2006), 'The life and world of a singer: Finding my way', Philosophy of Music Education Review, 14:1, pp. 65-77.

- (2015), 'The singularity of experience in the voice studio: A dialogue with Michel Henry', in K. Thomaidis and B. Macpherson (eds), Voice Studies: Critical Approaches to Process, Performance and Experience, Oxford and New York: Routledge, pp. 25-37.

Karantonis, Pamela, Placanica, Francesca and Verstraete, Pieter (eds) (2016), Cathy Berberian: Pioneer of Contemporary Vocality, New York: Routledge.

Koskoff, Ellen (ed.) (1989), Women and Music in Cross-Cultural Perspective, Chicago, IL: University of Illinois Press.

Krishna, Madabusi (2013), A Southern Music: The Karnatik Story, New Delhi: Harper Collins.

LaBelle, Brandon (2014), Lexicon of the Mouth: Poetics and Politics of Voice and the Oral Imaginary, New York and London: Bloomsbury Academic and Professional.

Macpherson, Ben (2012), 'A voice and so much more (or when bodies say things that words cannot)', Studies in Musical Theatre, 6:1, pp. 43-57.

_ (2015), 'Body musicality: The visual, virtual, visceral voice', in K. Thomaidis and B. Macpherson (eds), Voice Studies: Critical Approaches to Process, Performance and Experience, Oxford and New York: Routledge, pp. 149-60.

Mani, Charulatha (2007-15), 'Isai payanam - Ragas in Carnatic music, excerpts from isai payanam DVDs by giri trading', YouTube, https://www.youtube.

52. com/isaipayanam. Accessed 15 March 2019. 
(2017a), 'Singing across cultures: An auto-ethnographic study', 1. International Review of the Aesthetics and Sociology of Music, 48:2, pp. 245-64. 2.

- (2017b), 'Gesture in musical declamation: An intercultural approach', 3. Musicologist, 1:1, pp. 6-31.

4. - (2018a), 'Customised pedagogical tools to aid aural-oral transmission: 5. RagaCurve and gesture', Finnish Journal of Music Education, 21:1, pp. 31-54. 6. - (2018b), 'Monteverdi reimagined: L'Orfeo from a Carnatic perspec- 7. tive', YouTube, 25 April, https://youtu.be/9szMfVtHQmQ. Accessed 218. December 2019.

- (2018c), 'The Thiruppavai project: Karnatik Viruttam meets Recitar 10 Cantando', YouTube, 9 March, https://youtu.be/_8cx4KmwnM4. Accessed 11. 21 December 2019.

- (2019a), 'Approaching Italian gorgie through Karnatik brigha: An 13 essai on intercultural vocal transmission', Theatre, Dance and Performance 14. Training, 10:3, pp. 410-17.

- (2019b), 'CompoSing awareness: Approaching somaesthetics through 16. voice and yoga', Journal of Somaesthetics, 5:2, pp. 67-85. 17.

McAllister-Viel, Tara (2018). Training Actors' Voices: Towards an Intercultural/ 18. Interdisciplinary Approach, London: Routledge. 19.

McClary, Susan (1989), 'Constructions of gender in Monteverdi's dramatic 20. music', Cambridge Opera Journal, 1:3, pp. 203-23. 21.

Merleau-Ponty, Maurice ([1945] 1993), 'Cézanne's doubt', in G. A. Johnson 22. (ed.), The Merleau-Ponty Aesthetics Reader: Philosophy and Painting (trans. 23. Michael B. Smith), Evanston, IL: Northwestern University Press, pp. 59-75. 24.

Nancy, Jean-Luc (2007), Listening (trans. Charlotte Mandell), New York: 25. Fordham University Press. 26.

Nathan, Archana (2019), 'A year after \#MeToo rocked the Carnatic circuit, how 27. have the sabhas responded', The Hindu, 23 August, https://www.thehindu- 28. businessline.com/blink/know/metoo-and-carnatic-music/article29230876. 29. ece?fbclid=IwAR3F7reiHCd_dkJTMprl5cqyzYNPINZtXUtEB1QqW6ee- 30. dTc_yU-v9xf-BE\#. Accessed 31 August 2019. 31.

Novak, Jelena (2015), Postopera: Reinventing the Voice-Body, Farnham: Ashgate. 32.

Pesch, Ludwig (1999), The Illustrated Companion to South Indian Classical Music, 33. 2nd ed., New Delhi: Oxford University Press. 34.

Poizat, Michael (1992), The Angel's Cry: Beyond the Pleasure Principle in Opera 35. (trans. A. Denner), Ithaca, NY: Cornell University Press. 36.

Radhakrishnan, Mahesh (2016),'South Indian Carnatic singing and Irish Sean- 37. nós - an ethnographic, musical and linguistic comparison', Folk Life Journal 38. of Ethnological Studies, 54:1, pp. 32-48. 39.

Sastry, Sundaram (2017), 'Aruna Sairam presents 7 Swarangalum 540. isai arasigalum', YouTube, 13 January, https://www.youtube.com/ 41. watch?v=Lb09TekoAi4. Accessed 21 December 2019.

Schlichter, Annette (2011), 'Do voices matter? Vocality, materiality, gender 43. performativity', Body \& Society, 17:1, pp. 31-52. 44.

Soneji, Davesh (2011), Unfinished Gestures: Devadasis, Memory, and Modernity 45. in South India, Chicago, IL: University of Chicago Press. 46.

Srinivasan, Amrit (1985), 'Reform and revival: The devadasi and her dance', 47. Economic and Political Weekly, 20:44, pp. 1869-76. 48.

Stoever, Jennifer (2016), The Sonic Color Line: Race and the Cultural Politics of 49. Listening, New York: New York University Press. 50. 
1. Subramanian, Lakshmi (2006), From the Tanjore Court to the Madras Music

2. Academy: A Social History of Music in South India, New Delhi: Oxford 3. University Press.

4. Taruskin, Richard (1995), Text and Act: Essays on Music and Performance, New 5. York: Oxford University.

6. Terada, Yoshitaka (1996), 'Effects of nostalgia: The discourse of decline in Periya 7. Mèlam music of South India', Bulletin of the National Museum of Ethnology, 8. 21:4, pp. 921-39.

9. (2000), 'T. N. Rajarattinam pillai and caste rivalry in South Indian clas10. sical music', Ethnomusicology, 44:3, pp. 460-90.

11. Thomaidis, Konstantinos (2013a), 'The grain of a vocal genre: A compara12. tive approach to the singing pedagogies of EVDC integrative perfor13. mance practice, Korean Pansori, and the polish centre for theatre practices 14. "Gardzienice"', Ph.D. thesis, London: University of London, https://ethos. 15. bl.uk/OrderDetails.do?uin=uk.bl.ethos.591058. Accessed 5 February 2019.

16. - (2013b), 'The vocal body', in S. Reeve (ed.), Body and Performance: Ways 17. of Being a Body, vol. 2, Devon: Triarchy Press, pp. 85-98.

18. - (2014), 'Singing from stones: Physiovocality and Gardzienice's thea19. tre of musicality', in D. Symonds and M. Taylor (eds), Gestures in Music Theatre, New York: Oxford University Press, pp. 242-58.

Thomaidis, Konstantinos (2015), 'What is voice studies', in K. Thomaidis and B. Macpherson (eds), Voice Studies: Critical Approaches to Process, Performance and Experience, Abingdon: Routledge, pp. 214-16.

- (2017), Theatre and Voice, London: Macmillan International Higher Education.

- (2019), 'Editorial', Journal of Interdisciplinary Voice Studies, 4:1, pp. 3-6.

Thomaidis, Konstantinos and Macpherson, Ben (2015), 'Introduction: Voice(s) as a method and an in-between', in K. Thomaidis and B. Macpherson (eds), Voice Studies: Critical Approaches to Process, Performance and Experience, Oxford and New York: Routledge, pp. 3-9.

Thomaidis, Konstantinos and Magnat, Virginie (2017), 'Voicing belonging: Traditional singing in a globalised world', Journal of Interdisciplinary Voice Studies, 2:2, pp. 97-102.

Virno, Paolo (2003), Quando il verbo si fa carne: Linguaggio e natura umana (When the Verb becomes Flesh: Language and Human Nature), Turin: Bollati Boringhieri.

Viswanathan, Thanjavur and Allen, Matthew (2004), Music in South India: The Karnātak Concert Tradition and beyond: Experiencing Music, Expressing Culture, vol. 2, New York: Oxford University Press.

Weidman, Amanda (2001), 'Questions of voice: On the subject of "classical" music in South India', Ph.D. thesis, New York: Columbia University.

_ (2006), Singing the Classical, Voicing the Modern: The Postcolonial Politics of Music in South India, Durham, NC: Duke University Press.

\section{SUGGESTED CITATION}

Mani, Charulatha (2020), 'On breaking with', Journal of Interdisciplinary Voice Studies, 5:1, pp. 59-59, doi: https://doi.org/10.1386/jivs_00016_1 
Charulatha Mani is an internationally renowned vocal performer of Karnatik 2. music of South India, originally from Chennai, India. Currently settled in 3. Brisbane, Australia, Charu's vocal and compositional practice extends to 4. intercultural interpretations of Early Opera. She received her Ph.D. from 5. Queensland Conservatorium Griffith University, Brisbane, in August 20196 for her thesis on Hybridising Karnatik Music and Early Opera. She currently manages the Research Centre at the Queensland Conservatorium. She also lectures at various universities in the fields of music, entertainment business management and culture studies.

Contact: Queensland Conservatorium Research Centre, Griffith University, 12. South Bank Campus, PO Box 3428, South Bank 4101, Brisbane, Australia 13.

E-mail: c.mani@griffith.edu.au 14.

(D) https://orcid.org/0000-0002-8072-3895 16.

$\begin{array}{ll} & 17 . \\ \end{array}$

Charulatha Mani has asserted their right under the Copyright, Designs and 18. Patents Act, 1988, to be identified as the author of this work in the format that 19.
was submitted to Intellect Ltd.

$\begin{array}{ll} & 20 . \\ & \\ & \end{array}$. 